\title{
Retention of a passive avoidance response in mice
}

ROBERT CLARK

PHARMACEUTICALS RESEARCH DIVISION, E. I. DU PONT DE NEMOURS AND COMPANY, INC.

Mice were trained to avoid electric shock by means of a single trial passive avoidance conditioning procedure. Retention of the avoidance response was examined as a function of the time interval between training and retention testing $(0.5$ to $512 \mathrm{hr}$.) and the duration of punishing electric shock during training. The relation between retention and the logarithm of time was a decreasing essentially linear function of flat-slope, which was independent of a 4-fold change in shock duration. The time required for $50 \%$ of the animals to "forget" the avoidance response was estimated to be $1500 \mathrm{hr}$. Retention at a single time interval was invariant over a 4-fold change in shock intensity during training.

Although single trial passive avoidance conditioning techniques have been used to study the effects on retention of such factors as anesthetics (Abt, Essman, \& Jarvik, 1961), electroconvulsive shock (Madsen \& McGaugh, 1961), hypothermia (Essman \& Sudak, 1963) and spreading cortical depression (Pearlman \& Jarvik, 1961), the retention of passive avoidance behavior per se has not been systematically investigated. Since single trial conditioning methods offer certain advantages in studying the effects on retention of drugs and other biological variables it seemed of some interest to determine the relationship between response retention and the time interval between training and retention testing over a relatively extended time period. The possibility of modifying this relationship by manipulation of some of the parameters involved in the avoidance training procedure was also explored.

\section{Subjects and Apparatus}

Ss were female mice of the $\mathrm{CF}_{1}$ (Carworth Farms) strain ranging in weight from 16 to $25 \mathrm{gm}$, given continual access to food and water and housed in suspended 8 in. $x 10$ in. by 7 in. high wire mesh cages (10 mice/ cage) located in the same room in which the experiments were done.

The "step-through" apparatus (Essman \& Alpern, 1964) was a completely enclosed black plastic chamber approximately 12 in. square. A 1-1/2 in. circular hole in the front panel opened onto a stainless steel floor located inside the chamber. A metal perch $(1 / 2$ in. wide $\mathrm{x} 2$ in. long) was attached to the outside of the front panel at the base of the hole. A length of wire with a light metal clip on one end was attached to one terminal of a $1000-\mathrm{v}$ ac constant current shock power supply (Lehigh Valley Electronics, Fogelsville, Pennsylvania). A lead from the other terminal was connected to the metal floor inside the chamber. Shock duration was controlled by an electronic timer (Foringer and Company, Rockville, Maryland).

\section{Procedure}

Training consisted of placing each mouse on the metal perch with the metal clip attached to its tail 1-1/2 in. from the tip. When the mouse stepped through the hole and touched the metal floor inside the chamber with both forepaws, the experimenter applied a shock (by foot pedal switch) of specified amperage and duration to the animal. The time interval between placement on the perch and stepping into the chamber was recorded for each mouse and the animals which failed to stepthrough within $8 \mathrm{sec}$. were discarded (generally 10\% of mice tested). Control mice were treated in identical fashion except that the wire lead to the chamber was disconnected and therefore no shock was given. At some time after training, each experimental and each control mouse was given a single retention test which was identical to the training procedure described for the control animals. Animals which did not step through the hole and touch the metal floor with both forepaws within $30 \mathrm{sec}$. of placement on the perch were counted as having "retained" the passive avoidance response of remaining on the perch. The response latency of mice which stepped through the hole in less than $30 \mathrm{sec}$. was also recorded.

To study the time course of retention as a function of shock duration 18 groups of 40 mice each were trained with a shock intensity of $0.7 \mathrm{~mA}$ and shock durations of either $0.7,1.4$ or $2.8 \mathrm{sec}$. Six groups of 20 mice each served as controls. The time interval between training and retention testing was systematically varied between $30 \mathrm{~min}$. and $512 \mathrm{hr}$. (the time periods are indicated in Fig. 1 ).

To study retention at a single time interval as a function of shock intensity, seven groups of 20 mice

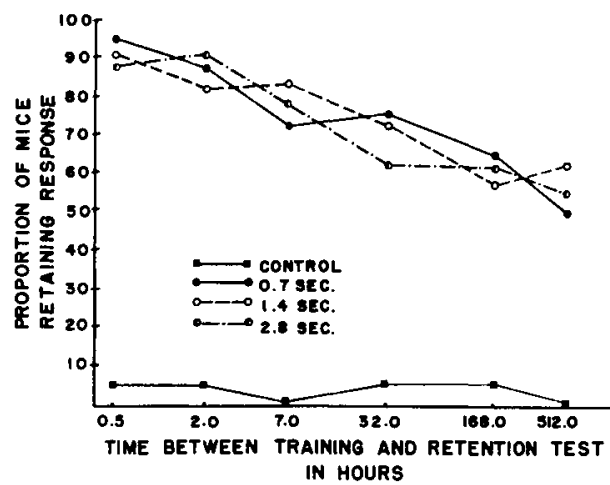

Fig. 1. Proportion of mice retaining a passive avoidance response as a function of the time interval between training and retention testing, and the shock duration during training when shock intensity was heId constant at $0.7 \mathrm{~mA}$. 
each were trained with shock intensities of either 0.0 (control), $0.1,0.2,0.4,0.8,1.6$ or $3.2 \mathrm{~mA}$. Shock duration was held constant at 1 sec., and all Ss were given a single retention trial $24 \mathrm{hr}$. after training.

Since failure to respond (i.e., not entering the chamber) was the indicator of retention in these experiments, there was a possibility that dissipation over time of non-specific depressant effects of electric shock could conceivably account for any loss in retention over time. In order to minimize stimulus generalization and thereby test for the effects of shock per se on later retention, 20 "shock-control" mice were individually placed in a small white chamber (6 in. square) containing a grid floor, and administered a scrambled shock of $1.0 \mathrm{~mA}$ for $1 \mathrm{sec}$. applied to the feet. One hr. later these animals were given a retention test in the step-through apparatus.

\section{Results and Discussion}

Figure 1 shows the proportion of experimental and control Ss which retained the passire avoidance response (i.e., failed to enter the chamber within $30 \mathrm{sec}_{.}$) as a function of the time interval between training and retention testing, and the shock duration during training. The proportion of mice which retained the response in each of the three shock duration groups decreased in an approximately linear fashion over time when these data were plotted as a function of the logarithm of time. An equation of the form $y=a^{x}+b$ could therefore adequately describe the three retention curves of Fig. 1. Retention curves of similar form have been obtained from human Ss in a variety of learning situations (Howland, 1951). Each of the differences between each experimental value and its corresponding control value was significant at the 0.01 level or beyond by chi-square test (one-tail). None of the differences among the three experimental curves was significant at the 0.05 level or beyond by chi-square test (twotail), which indicates that retention was invariant over a 4-fold increase in shock duration during training. Each experimental curve showed a decreasing trend significant at beyond the 0.01 probability level when the " $\mathrm{T}$ " statistic of Rumke \& de Jonge (1964) was applied to be the experimental data. This indicates that retention significantly decreased as a consequence of the time interval between training and retention testing. The time required for $50 \%$ of the animals to fail to retain the passive avoidance response was estimated to be $1500 \mathrm{hr}$. based upon the extrapolation of a straight line fitted to the combined means of the three experimental curves in Fig. 1.

The proportion of mice which retained the avoidance response $24 \mathrm{hr}$. after training as a function of shock intensities of either 0.0 (control), $0.1,0.2,0.4,0.8$, 1.6, or $3.2 \mathrm{~mA}$ during training was $5.0,0.0,12.5,20.0$, $60.0,57.5$, and 60.0 respectively. Retention values corresponding to shock intensities of $0.4 \mathrm{~mA}$ and greater were significantly different from the control value at the 0.05 level or beyond by chi-square test (one-tail). Retention values approximating 60\% which corresponded to the $0.8,1.6$ or $3.2 \mathrm{~mA}$ intensities did not differ significantly from one another by chi-square test (two-tail). These data indicate that retention at a single time interval was invariant over at least 4-fold increase in shock intensity during training and that maximum retention at $24 \mathrm{hr}$. did not exceed $60 \%$.

The proportion of "shock control" Ss which failed to remain on the perch during the "retention test" was $10 \%$, a value no different from that of the non-shocked control animals. It is unlikely, then, that non-specific depressant effects of electric shock could account for the experimental data which have been presented.

\section{References}

Abt, J. P., Essman, W. B., \& Jarvik, M. E. Ether-induced retrograde amnesia for one-trial conditioning in mice. Science, 1961. $133,1477-1478$.

Ess.nan, W. B., \& Alpern, H.

Essman, W. B., \& Alpern, H. Single trial conditioning: Methodology and results with mice. Psychol. Rep., 1964, 14, 731-740.

Essman, W. B., \& Sudak, F. N. Effect of hypothermia on the establishment of a conditioned avoidance response in mice. J. comp. physiol. Psychol., 1963, 56, 366-369.

Howland, C. I. Human learning and retention. In S. S. Stevens (Ed.), Handbook of experimental psychology. New York: John Wiley and Sons, Inc., 1951. Pp. 613-689.

Madsen, M. C., \& McGaugh, J. L. The effect of electroshock on one trial avoidance learning. J. comp. physiol. Psychol., 1961, $54,522-523$.

Peariman, C. A., Jr., \& Jarvik, M. E. Retrograde amnesia produced by spreading cortical depression. Fed. Proc., 1961, 20, 340 .

Rumke, Chr. L., \& De J mge, H. Design, statistical analyses and interpretation. In Laurence and Bacharach (Eds.), Evaluation of drug activities: pharmacometrics. Vol. 1, New York: Academic Press, 1964. Pp. 47-110. 